Published in final edited form as:

Addict Behav. 2014 October ; 39(10): 1441-1446. doi:10.1016/j.addbeh.2014.05.012.

\title{
Beliefs and Attitudes Regarding Drug Treatment: Application of the Theory of Planned Behavior in African American Cocaine Users
}

\author{
Brenda M. Booth, $\mathrm{PhD}^{1,2}$, Katharine E. Stewart, PhD, MPH ${ }^{3,4}$, Geoffrey M. Curran, $\mathrm{PhD}^{1,2}$, \\ Ann M. Cheney, $\mathbf{P h D}^{1,2}$, and Tyrone F. Borders, $\mathbf{P h D}^{5}$ \\ ${ }^{1}$ University of Arkansas for Medical Sciences, Psychiatric Research Institute, Division of Health \\ Services Research, 4301 W. Markham St., Slot 755, Little Rock, AR 72205 \\ ${ }^{2}$ Center for Mental Healthcare and Outcomes Research, 2200 Ft Roots Dr, Bldg 58, Central \\ Arkansas Veterans Healthcare System, Little Rock, AR 722114 \\ ${ }^{3}$ University of North Carolina General Administration, 910 Raleigh Road P.O. Box 2688, Chapel \\ Hill, NC 27514
}

${ }^{4}$ University of North Carolina at Charlotte, Department of Public Health Sciences, 9201 University City Blvd, Charlotte, NC 28223

${ }^{5}$ University of Kentucky, College of Public Health, Department of Health Services Management and Policy, 111 Washington Ave, Lexington, KY 40536

\begin{abstract}
Background-The Theory of Planned Behavior (TPB) can provide insights into perceived need for cocaine treatment among African American cocaine users.

Methods-A cross-sectional community sample of 400 (50\% rural) not-in-treatment African American cocaine users was identified through respondent-driven sampling in one urban and two rural counties in Arkansas. Measures included self-reports of attitudes and beliefs about cocaine treatment, perceived need and perceived effectiveness of treatment, and positive and negative cocaine expectancies. Normative beliefs were measured by perceived stigma and consequences of
\end{abstract}

(C) 2014 Elsevier Ltd. All rights reserved.

Corresponding Author: Brenda M. Booth, Psychiatric Research Institute \#755, University of Arkansas for Medical Sciences, $4301 \mathrm{~W}$. Markham St., Little Rock, AR 72205, USA, boothbrendam@uams.edu; telephone 1-501-526-8129, 1-501-526-8199 (fax).

Contributors

Drs. Booth, Curran, Stewart, and Borders designed the study and wrote the protocol; Dr. Booth conducted the statistical analyses and wrote early drafts of the report; Drs. Curran, Stewart, Cheney, and Borders all commented on various drafts and Dr. Cheney assisted with literature review.

All authors contributed to and have approved the final manuscript.

Conflict of Interest

All authors declare no conflicts of interest.

The content is solely the responsibility of the authors and does not necessarily represent the official views of the National Institutes of Health or reflect the position or policy of the Department of Veterans Affairs or the United States government.

Publisher's Disclaimer: This is a PDF file of an unedited manuscript that has been accepted for publication. As a service to our customers we are providing this early version of the manuscript. The manuscript will undergo copyediting, typesetting, and review of the resulting proof before it is published in its final citable form. Please note that during the production process errors may be discovered which could affect the content, and all legal disclaimers that apply to the journal pertain. 
stigma regarding drug use and drug treatment. Perceived control was measured by readiness for treatment, prior drug treatment, and perceived ability to cut down on cocaine use without treatment.

Findings-Multiple regression analysis found that older age (standardized regression coefficient $\beta=0.15, P<0.001)$, rural residence $(\beta=-0.09, P=0.025)$, effectiveness of treatment $(\beta=0.39, P$ $<0.001)$, negative cocaine expectancies $(\beta=0.138, P=0.003)$, experiences of rejection $(\beta=0.18$, $P<0.001)$, need for secrecy $(\beta=0.12, P=0.002)$, and readiness for treatment $(\beta=0.15, P<$ 0.001 ), were independently associated with perceived need for cocaine treatment.

Conclusions-TPB is a relevant model for understanding perceived need for treatment among African American cocaine users. Research has shown perceived need to be a major correlate of treatment participation. Study results should be applicable for designing interventions to encourage treatment participation.

\section{Keywords}

perceived need for treatment rural; Theory of Planned Behavior; Treatment beliefs and attitudes

\section{Introduction}

National survey data indicate that the vast majority of individuals with drug use disorders do not receive treatment. For example, in the 2010 National Survey on Drug Use and Health (NSDUH), only $8.1 \%$ of individuals needing treatment (those with past-year substance abuse or dependence by DSM-IV criteria) reported receiving either formal or informal treatment in the previous 12 months (Substance Abuse and Mental Health Services Administration, 2011). Concomitant with lack of treatment utilization is a low rate of selfreported need for treatment ("perceived need"). In the same NSDUH survey, 95\% of those with a substance use disorder stated that they did not need treatment.

Multiple studies have examined factors associated with treatment utilization based on the approach of Aday and Andersen (Aday \& Andersen, 1974) that defines predisposing factors (e.g, demographic factors), enabling factors (e.g., access) and need factors (e.g., illness severity) as predictors of health care utilization (Booth, Kirchner, Fortney, Ross, \& Rost, 2000; Carlson, et al., 2010; Kaskutas, Weisner, \& Caetano, 1997; Weisner, 1990). However, few reports examine the role of attitudes or beliefs related to treatment utilization, including perceived need for treatment. When perceived need is specifically included, it is significantly associated with treatment entry over three years, with hazard ratios of 1.3 and 2.05 (Carlson, et al., 2010; Siegal, Falck, Wang, \& Carlson, 2002). Other researchers have used terms implying or including perceived need. Neff and Zule (Neff \& Zule, 2002) have argued that perceived need is a component of "treatment readiness." A readiness for treatment scale composed of "desire to go to treatment" and "how soon individual would want to go" significantly predicted treatment initiation at 3 and 6 months (Wechsberg, Zule, Riehman, Luseno, \& Lam, 2007) and a similar scale was associated with retention in longterm methadone treatment (Joe, Simpson, \& Broome, 1998).

Yet perceived need may be associated with other beliefs and attitudes (Mojtabai, Olfson, \& Mechanic, 2002). Many studies have focused on "motivation," which should be directly 
related to perceived need but also may be associated with other constructs, such as desire for help and recognition of the problems resulting from substance use (D. Longshore \& Teruya, 2006; D. L. Longshore, Grills, Anglin, \& Annon, 1997; Nwakeze, Magura, \& Rosenblum, 2002), or in a "stage of change" framework where motivation is the first step in preparing for change and problem recognition (D. Longshore \& Teruya, 2006).

However, most studies that examine intrapersonal factors and their influence on treatment utilization explore such factors in isolation or are atheoretical. The Theory of Planned Behavior (TPB) (Ajzen, 1991) may be useful for examining these issues. According to this model, a given behavior (e.g., treatment seeking or treatment utilization) is preceded and predicted by one's intentions (Ajzen, 2001, 2002), which can be approximated by perceived need, assuming that perceived need is a component of intention to seek treatment. Those intentions are in turn preceded by three distinct types of beliefs: attitudes and beliefs about the behavior and its sequelae, beliefs about the social norms surrounding the behavior (perceived norms), and beliefs about the individual's personal ability to engage in the behavior and his/her control over the behavior (perceived control). TPB has been used elsewhere to study treatment entry/intention to seek treatment for individuals with mental illness as well as attitudes toward drinking (Britt, et al., 2011; Stecker, Fortney, Hamilton, \& Aizen, 2007; Wall, Hinson, \& McKee, 1998; Westerhof, Maessen, de Bruijn, \& Smets, 2008).

Attitudes and beliefs about the behavior can be measured by a variety of inventories for substance abuse or mental health problems. Several studies have explored outcome "expectancies", defined in social learning theory as the sequelae that an individual expects will result from a given behavior (Cooper, Frone, Russell, \& Mudar, 1995; Wall, et al., 1998). Expectancies have been studied in terms of relapse for a range of substance use disorders (Kristjansson, Agrawal, Lynskey, \& Chassin, 2012; Linkovich-Kyle, Schreiner, \& Dunn, 2012; Smith, Goldman, Greenbaum, \& Christiansen, 1995). Beliefs about social norms can be captured by measures of stigma, which reflect the individual's sense of community norms. Stigma has been extensively examined by a multidimensional measure pertaining to mental illness developed by Link and colleagues and validated longitudinally (Link, Struening, Rahav, Phelan, \& Nuttbrock, 1997). Beliefs about behavioral control can be measured by belief in the ability to reduce or stop drug use on one's own without treatment and an individual's perception of personal readiness to engage in the behavior. Behavioral control can also include a history of previous drug treatment, a variable widely shown to predict treatment initiation (Booth, et al., 2000; Carlson, et al., 2010), assuming that prior treatment is an indicator of prior control or attempted control.

In conclusion, the TPB may be particularly relevant to the study of perceived need for treatment among substance users. We investigated TPB-based correlates of perceived need for treatment in a large cross-sectional sample $(\mathrm{N}=400)$ of rural and urban African American cocaine users. Cocaine is increasingly prevalent among rural African Americans especially in the majority African American counties bordering or close to the Mississippi River (Booth, Leukefeld, Falck, Wang, \& Carlson, 2006). The study was comprised of a single interview. With no prospective longitudinal data with which to study actual treatment entry in previous work (Booth, et al., 2000; Carlson, et al., 2010), we focused on the TPB to 
identify potential correlates of perceived need given its strong association with treatment participation.

\section{Materials and Methods}

\subsection{Study Overview}

Structured in-person interviews were conducted with 400 African American cocaine users (200 rural and 200 urban) using standardized instruments, pertinent measures from prior rural substance abuse research, and newly developed questions based on initial qualitative work. The sample size of 400 was chosen to maximize power while staying within budget constraints. The university's institutional review board approved the study, written informed consent was obtained from all participants, and the National Institute on Drug Abuse issued a Certificate of Confidentiality to protect the privacy of research subjects

\subsection{Eligibility Criteria}

Participants had to: 1) be at least 18 years old; 2) be of African American race; 3) report cocaine use at least 2 times in the past 30 days by any route other than injection; 4) report no formal drug abuse treatment/counseling/self-help meetings in the past 30 days; 5) reside in one of the study counties and provide a verifiable address. Cocaine injectors were excluded because a prior study in the same population indicated that injection was extremely rare (Booth, et al., 2006).

\subsection{Recruitment and Sampling}

Two eastern Arkansas rural counties, Lee and St. Francis, meet the U.S. Census Bureau definition of rural, are majority African American, and have high rates of poverty (U.S. Census Bureau, 2010). The one urban county, Pulaski, is in the center of the state, has a total population of 382,748 (35\% African American), and has fewer residents below the poverty level (U.S. Census Bureau, 2010).

We used Respondent-Driven Sampling (RDS) (Draus, Siegal, Carlson, Falck, \& Wang, 2005; Heckathorn, 1997, 2002) to identify and recruit participants. RDS is useful for finding "hidden populations" such as illicit drug users and has been shown to produce a more representative sample of hidden populations than that obtained through targeted or snowball sampling (Heckathorn, Semaan, Broadhead, \& Hughes, 2002). A sample obtained using RDS can be expected to merge into stable characteristics of the population being studied after multiple recruitment waves (Heckathorn, 1997, 2002; Wang, Falck, Li, Rahman, \& Carlson, 2007).

In each county, preliminary ethnographic methods were used to identify "seeds" who met study criteria (Draus, et al., 2005), including "hanging out" in propitious locations such as bars, talking to community members about their knowledge of drug use, and meeting with treatment providers. Anyone having contacts with drug users was provided with study "business" cards to pass on to users, who had to initiate contact themselves directly with study staff to maintain confidentiality. Study seeds and participants who completed the baseline interview were asked to give referral coupons to people they knew who were "like 
them." If referrals resulted in study contact, the seeds received \$10 per contact for up to three contacts, but up to six referrals were allowed. Specific study eligibility criteria were not communicated to avoid ineligible subjects "faking" criteria to obtain study remuneration. Participants who completed an interview were reimbursed $\$ 50$ plus $\$ 10$ for travel expenses. Recruitment was targeted to be at least one-third female, approximately balanced between crack cocaine users and powder cocaine users, and well distributed by age.

\subsection{Measures}

We developed four parallel "rulers" (visual analog scales) scored from 1 to 10 based on research measuring readiness to change with rulers rather than by specific "stages" with acceptable psychometrics (Heather, Smailes, \& Cassidy, 2008; Korcha, et al., 2012; Maisto, et al., 2011).

The Perceived Need Ruler instructed participants to score 1, 2, or 3 if they felt no need for treatment; 4, 5, 6, or 7 if "sometimes I think I need treatment;" and 8, 9, or 10 if they "need treatment right now." One visual analog ruler was included in the attitudes/beliefs domain: the "Effectiveness Ruler" was phrased "Do you think addiction treatment would be effective at helping you make a change (quit or cut down) in your use of cocaine?" Behavioral control was measured by two visual analog rulers: the "Readiness Ruler" asked "How ready you are to make a change (quit or cut down) in your use of cocaine?" The "Capability Ruler" asked "How capable you are of making a change on your own (quitting or cutting down) in your use of cocaine?"

Cocaine expectancies, also included in the attitudes/beliefs domain, were measured by the 31-item "Cocaine Effects Questionnaire" (CEQ), the only cocaine expectancy measure based solely on data from active or in-treatment cocaine users (Rohsenow, Sirota, Martin, \& Monti, 2004). The CEQ asks "what you personally experienced while using cocaine in the past year" on a 7-point scale from "never" to "always" and participants were instructed to answer the questions for when they "are high on cocaine, not when it wears off."

To measure beliefs about social norms surrounding drug use and treatment, we used the 36item measure of mental illness stigma from the work of Bruce Link (Link, et al., 1997) rephrased for drug use rather than mental illness where appropriate.

\subsection{Data Analysis}

We examined demographic and theory-based variables' bivariate associations with the perceived need ruler, using non-parametric bivariate analyses given the non-normal distribution of the perceived need ruler. However, we used ordinary least squares regression (OLS) given the large sample size, the dependent variable being relatively continuous, and assuming lower urgency of non-normally distributed residuals (Gelman \& Hill, 2007). Several of the stigma variables had some missing data (of these, 11 had only 1 missing value, 1--2 missing, 5--3 missing, 4--4 missing, 1--5 missing, and only 3 had 7 missing values) so we imputed these missing values using SAS PROC MI and calculated final regression models using SAS PROC MIANALYZE (SAS Institute Inc., 2011). For the multivariate analysis, we generated a parsimonious model with all independent correlates 
but age, gender, and rural residence were "forced" inclusions given they were sampling variables.

\subsection{Results}

\subsection{Sample Characteristics}

Two hundred urban and 200 rural African American cocaine users were recruited May 2011-April 2012. On average, the sample was male, late thirties in age, seldom married or living as married, and not employed (Table 1). Almost 60\% (58.8\%) reported no history of drug treatment; $9.5 \%(n=38)$ reported drug treatment in the past year. Rural participants were more likely to report at least part-time employment, more days' marijuana use and powder cocaine use (Table 1). The mean for the Perceived Need Ruler was 5.3 (S.D. $=2.8$ ) and the median response was 5; 13\% rated their need as "right now," (scored 10), 14\% rated need as "absolutely no need" (scored 1 ).

\subsection{Bivariate Associations}

We calculated the "higher order components" found originally for the CEQ (Rohsenow, et al., 2004) as separate sums of the positive and negative items, and the stigma scales (Link, et al., 1997). On a bivariate basis, perceived need for cocaine treatment was associated with being employed vs. unemployed and with prior drug treatment but not with gender, education, partnered status, or rural residence (Table 2). Perceived need for cocaine treatment was significantly associated with both positive cocaine expectancies and negative cocaine expectancies, and was strongly correlated with perceived effectiveness of treatment and readiness to change one's cocaine use, but was not correlated with perceived ability to cut down or eliminate cocaine use on one's own. Two stigma scales were significantly correlated with perceived need for cocaine treatment: experiences of rejection, and need for secrecy regarding drug use (Table 2).

\subsection{Multivariate Models for Perceived Need}

Multivariate OLS models, including the three forced demographic variables (gender, location, and age), found that two measures of beliefs and intentions [the effectiveness ruler ( $\beta=0.39)$ and negative cocaine expectancies $(\beta=0.13)$ ], two measures of normative beliefs [experiences of rejection $(\beta=0.18)$ and need for secrecy $(\beta=0.12)$ ], and one measure of perceived control [the readiness ruler (standardized $\beta=0.15$ )], were all highly significantly associated with perceived need (see Table 3$)$. Also significant were age $(\beta=0.15)$ and rural residence $(\beta=-0.09$ ). Regression coefficients for all significant variables but rural residence were positive, indicating direct associations with perceived need for cocaine treatment. The final model explained a large (42\%) proportion of total variance. Other measures of perceived control, including the belief in being able to cut down or quit cocaine use on one's own and previous drug treatment, were not significant. In exploratory analysis, we found that prior treatment was strongly and positively correlated with all significant variables in the final model (data not reported in tables). We also found that rural residents had significantly higher scores on the rejection scale, and higher scores on the Readiness and Effectiveness Rulers and negative cocaine expectancies. 


\subsection{DISCUSSION}

Our findings indicate that the Theory of Planned Behavior is very relevant for informing understanding of perceived need for cocaine treatment, even though perceived need may capture only some aspects of behavioral intention. Our model accounted for $42 \%$ of the variance in perceived need for treatment, which is consistent with meta-analyses suggesting that the combination of behavioral attitudes/beliefs, perceived social norms, and perceived behavioral control account for 40 to $50 \%$ of the variance in behavioral intentions overall (Godin \& Kok, 1996; S. Sutton, 1998).

In terms of attitudes and beliefs, we found that negative cocaine expectancies, but not positive expectancies, were associated with perceived need. It may be that negative expectancies are more salient for individuals considering their need for treatment; belief salience has been discussed as a critical aspect of the attitudes/beliefs construct in reviews of TPB (Connor \& Armitage, 1998) as well as by Ajzen and his colleagues (Ajzen, Nichols, \& Driver, 1995).

Although we found that one measure of perceived control, readiness to enter treatment, was associated with perceived need, another measure, perceived capability to cut down on drug use, was not. This finding may be due to the fact that perceived control and self-efficacy are considered to be highly behavior-specific (i.e., an individual may have high perceived control over one behavior such as drug use but lower perceived control over a related behavior such as entry into treatment) (Bandura, 1977, 1982). Future investigations of perceived need for treatment and treatment entry/utilization should explore perceived control over several related behaviors, including drug use, entry into treatment, and engagement with treatment to identify which aspects of perceived control are most critical.

Prior drug treatment, which we conceptualized as a proxy for perceived control, was also not a significant predictor of perceived need in our multivariate model but was significantly correlated with attitudes and normative beliefs in bivariate exploratory analyses. This is consistent with some theorists' conceptualizations of TPB (Connor \& Armitage, 1998; Hagger, Chatzisarantis, \& Biddle, 2002), which suggest that past behavior may best be treated as a construct separate from attitudes, social norms, and perceived control, given its association with all of these constructs and the repeated finding that past behavior serves as a potential moderating factor in the model.

Compared to other cognitive models of health behavior, such as the Health Belief Model (HBM), TPB focuses more explicitly on the connection between behavioral intentions and the behaviors themselves and, like social cognitive theory, specifies the importance of perceived control. The addition of perceived control allows the TPB to address in a more specific way, compared to other theories, the fact that many health behaviors are not entirely under an individual's voluntary control (S. Sutton, 2001). This lack of control may be for a variety of reasons, such as the direct involvement of another individual in the behavior (e.g., sexual behavior) or the complicating factor of addiction (e.g., smoking cessation or engagement in drug treatment). Our finding that even a broad measure of perceived control, the readiness ruler, is strongly associated with perceived need for treatment provides 
additional support for including this construct in models of behavior and, thus, interventions to enhance intentions to engage in drug treatment.

Two significant measures independently associated with perceived need, experiences of rejection associated with drug use or treatment and need for secrecy regarding drug use or treatment, point to the importance of these aspects of stigma as a potential motivator of behavior. Secrecy is a component of the response to stigma (Link, et al., 1997) and, with experiences of rejection, seems to be a strong correlate of perceived need. Various forms of discrimination can have substantial negative influences on medical and physical health (Krieger, 2000; Krieger \& Davey Smith, 2004; Williams \& Williams-Morris, 2000), but in this instance stigma appears to be a positive motivator towards better health associated with treatment.

It is noteworthy that a substantial proportion of the sample (18\%) rated their need for treatment as either " 1 " or " 2 ," indicating very definitely "no need." On the other hand, almost $15 \%$ rated their need as "right now," or 9-10, and almost half (44.5\%) said they "sometimes" felt they needed treatment. This distribution suggests that interventions to increase treatment engagement might focus on those with at least a median score (5) or more on the scale, perhaps using a case management approach that has been shown to be effective at increasing treatment engagement (Rapp, et al., 2008).

Rural participants identified significantly less need for treatment compared to urban participants only in multivariate analysis, probably because of collinearity with strong correlates of perceived need. Thus, all things being equal, rural participants did perceive lower need. It may be that lower geographic access to drug treatment in Arkansas rural areas (Carlson, et al., 2010) induces a sense of lower need, especially given lower availability of transportation for very low income populations. Efforts targeting rural cocaine users might include campaigns about the benefits of illicit drug use treatment, given the success of public programs to raise awareness about depression treatment.

Our findings also have potential implications for substance abuse policy and treatment administration. Drug treatment providers may need to improve both the actual or public images of their effectiveness. Treatment programs may need to increase measures to secure client anonymity. Further research on how to assure confidentiality is needed, but colocating treatment programs in medical care or general office buildings may be beneficial, especially in rural communities.

This report has a major limitation that the data were obtained from a single interview without data to determine the behavioral outcome, treatment participation. However, prior research on perceived need specifically (Carlson, et al., 2010; Siegal, et al., 2002) as well as on motivation/treatment readiness in general (D. Longshore \& Teruya, 2006; D. L. Longshore, et al., 1997; Neff \& Zule, 2002; Nwakeze, et al., 2002) either explicitly or implicitly assume that these factors are strongly associated with treatment utilization.

In conclusion, multiple reports have documented that most individuals with substance abuse issues do not attend treatment. Analysis of perceived need for cocaine treatment among 400 African American cocaine users found that TPB is helpful in understanding key attitudes 
and beliefs associated with perceived need for drug treatment. These findings can potentially inform interventions to increase treatment utilization.

\section{Acknowledgments}

We thank Xiaotong Han, M.S., for assistance with statistical analysis

Research reported in this publication was supported by the National Institute on Drug Abuse of the National Institutes of Health under Award Number RO1DA026837 to Dr. Tyrone Borders while at the University of Arkansas for Medical Sciences. The funding agency had no role in the design, collection, analysis, or interpretation of data, nor the writing of the manuscript or decision to submit the manuscript for publication. We thank Xiaotong Han, M.S., for assistance with statistical analyses.

\section{Abbreviations}

$\begin{array}{ll}\text { CEQ } & \text { Cocaine Effects Questionnaire } \\ \text { NSDUH } & \text { National Survey on Drug Use and Health } \\ \text { OLS } & \text { Ordinary Least Squares Regression } \\ \text { RDS } & \text { Respondent-Driven Sampling } \\ \text { TPB } & \text { Theory of Planned Behavior }\end{array}$

\section{References}

Aday LA, Andersen R. A framework for the study of access to medical care. Health Serv Res. 1974; 9:208-220. [PubMed: 4436074]

Ajzen I. The theory of planned behavior. Organizational Behavior and Human Decision Processes. 1991; 50:179-211.

Ajzen I. Nature and operation of attitudes. Annu Rev Psychol. 2001; 52:27-58. [PubMed: 11148298]

Ajzen I. Perceived behavioral control, self-efficacy, locus of control, and the theory of planned behavior. Journal of Applied Social Psychology. 2002; 32:665-683.

Ajzen I, Nichols AJ, Driver BL. Identifying salient beliefs about leisure activities: Frequency of elicitation versus response latency. Journal of Applied Social Psychology. 1995; 25:1391-1410.

Bandura A. Self-efficacy: toward a unifying theory of behavioral change. Psychol Rev. 1977; 84:191215. [PubMed: 847061]

Bandura A. Self-efficacy mechanism in human agency. The American Psychologist. 1982; 37:122147.

Booth BM, Kirchner J, Fortney J, Ross R, Rost K. Rural at-risk drinkers: correlates and one-year use of alcoholism treatment services. Journal of Studies on Alcohol. 2000; 61:267-277. [PubMed: 10757138]

Booth BM, Leukefeld C, Falck R, Wang J, Carlson R. Correlates of rural methamphetamine and cocaine users: results from a multistate community study. Journal of Studies on Alcohol. 2006; 67:493-501. [PubMed: 16736068]

Britt TW, Bennett EA, Crabtree M, Haugh C, Oliver K, McFadden A, Pury CLS. The Theory of Planned Behavior and reserve component veteran treatment seeking. Military Psychology. 2011; 23:82-96.

Carlson RG, Sexton R, Wang J, Falck R, Leukefeld CG, Booth BM. Predictors of substance abuse treatment entry among rural illicit stimulant users in Ohio, Arkansas, and Kentucky. Substance Abuse. 2010 Jan.31:1-7. [PubMed: 20391264]

Connor M, Armitage CJ. Extending the Theory of Planned Behavior: A review and avenues for further research. Journal of Applied Social Psychology. 1998; 28:1429-1464. 
Cooper ML, Frone MR, Russell M, Mudar P. Drinking to regulate positive and negative emotions: a motivational model of alcohol use. J Pers Soc Psychol. 1995; 69:990-1005. [PubMed: 7473043]

Draus PJ, Siegal HA, Carlson RG, Falck RS, Wang J. Cracking the cornfields: Recruiting illicit stimulant drug users in rural Ohio. Sociology Quarterly. 2005; 46:165-189.

Gelman, A.; Hill, J. Data analysis using regression and multilevel/hierarchical models. New York, NY: Cambridge University Press; 2007.

Godin G, Kok G. The theory of planned behavior: a review of its applications to health-related behaviors. American journal of health promotion : AJHP. 1996; 11:87-98. [PubMed: 10163601]

Hagger MS, Chatzisarantis NLD, Biddle SJH. A Meta-Analytic Review of the Theories of Reasoned Action and Planned Behavior in Physical Activity: Predictive Validity and the Contribution of Additional Variables. Journal of Sport and Exercise Psychology. 2002; 24:3-32.

Heather N, Smailes D, Cassidy P. Development of a readiness ruler for use with alcohol brief interventions. Drug and Alcohol Dependence, Dec. 2008; 1:235-240.

Heckathorn DD. Respondent-driven sampling: A new approach to the study of hidden populations. Social Problems. 1997; 44:174-199.

Heckathorn DD. Respondent-driven sampling II: Deriving valid population estimates from chainreferral samples of hidden populations. Social Problems. 2002; 49:11-34.

Heckathorn DD, Semaan S, Broadhead RS, Hughes JJ. Extension of respondent-driven sampling: A new approach to the study of injection drug users aged 18-25. AIDS Behavior. 2002; 6:55-67.

Joe GW, Simpson DD, Broome KM. Effects of readiness for drug abuse treatment on client retention and assessment of process. Addiction. 1998; 93:1177-1190. [PubMed: 9813899]

Kaskutas LA, Weisner C, Caetano R. Predictors of help seeking among a longitudinal sample of the general population, 1984-1992. Journal of Studies on Alcohol. 1997 Mar.58:155-161. [PubMed: 9065893]

Korcha RA, Cherpitel CJ, Moskalewicz J, Swiatkiewicz G, Bond J, Ye Y. Readiness to change, drinking, and negative consequences among Polish SBIRT patients. Addictive Behavior. 2012 Mar.37:287-292.

Krieger, N. Discrimination and Health. In: Berkman, L.; Kawachi, I., editors. Social Epidemiology. Oxford: Oxford University Press; 2000. p. 36-75.

Krieger N, Davey Smith G. "Bodies count," and body counts: social epidemiology and embodying inequality. Epidemiol Rev. 2004; 26:92-103. [PubMed: 15234950]

Kristjansson SD, Agrawal A, Lynskey MT, Chassin LA. Marijuana expectancies and relationships with adolescent and adult marijuana use. Drug Alcohol Depend. 2012; 126:102-110. [PubMed: 22682980]

Link BG, Struening EL, Rahav M, Phelan JC, Nuttbrock L. On stigma and its consequences: evidence from a longitudinal study of men with dual diagnoses of mental illness and substance abuse. J Health Soc Behav. 1997; 38:177-190. [PubMed: 9212538]

Linkovich-Kyle TL, Schreiner AM, Dunn ME. Modeling the activation of tobacco smoking expectancies in memory in relation to use patterns. Addict Behav. 2012; 37:528-532. [PubMed: 22178600]

Longshore D, Teruya C. Treatment motivation in drug users: a theory-based analysis. Drug Alcohol Depend. 2006; 81:179-188. [PubMed: 16051447]

Longshore DL, Grills C, Anglin MD, Annon K. Desire for help among African-American drug users. Journal of Drug Issues. 1997; 27:755-770.

Maisto SA, Krenek M, Chung T, Martin CS, Clark D, Cornelius JA. A comparison of the concurrent and predictive validity of three measures of readiness to change alcohol use in a clinical sample of adolescents. Psychological Assessment. 2011 Dec.23:983-994. [PubMed: 21767028]

Mojtabai R, Olfson M, Mechanic D. Perceived need and help-seeking in adults with mood, anxiety, or substance use disorders. Arch Gen Psychiatry. 2002; 59:77-84. [PubMed: 11779286]

Neff JA, Zule WA. Predictive validity of a measure of treatment readiness for out-of-treatment drug users: enhancing prediction beyond demographic and drug history variables. Am J Drug Alcohol Abuse. 2002; 28:147-169. [PubMed: 11853130] 
Nwakeze PC, Magura S, Rosenblum A. Drug problem recognition, desire for help, and treatment readiness in a soup kitchen population. Subst Use Misuse. 2002; 37:291-312. [PubMed: $11913905]$

Rapp RC, Otto AL, Lane DT, Redko C, McGatha S, Carlson RG. Improving linkage with substance abuse treatment using brief case management and motivational interviewing. Drug and Alcohol Dependence. 2008 Apr.1:172-182. [PubMed: 18242883]

Rohsenow DJ, Sirota AD, Martin RA, Monti PM. The Cocaine Effects Questionnaire for patient populations: development and psychometric properties. Addict Behav. 2004; 29:537-553. [PubMed: 15050672]

SAS Institute Inc. SAS Version 9.3. Cary, NC: SAS Institute Inc; 2011.

Siegal HA, Falck RS, Wang J, Carlson RG. Predictors of drug abuse treatment entry among crackcocaine smokers. Drug and Alcohol Dependence. 2002 Oct.1:159-166. [PubMed: 12234645]

Smith GT, Goldman MS, Greenbaum PE, Christiansen BA. Expectancy for social facilitation from drinking: the divergent paths of high-expectancy and low-expectancy adolescents. J Abnorm Psychol. 1995; 104:32-40. [PubMed: 7897051]

Stecker T, Fortney JC, Hamilton F, Aizen I. An assessment of beliefs about mental health care among Veterans who served in Iraq. Psychiatric Services. 2007 Oct.58:1358-1361. [PubMed: 17914017]

Substance Abuse and Mental Health Services Administration. SAMHSA's Latest National Survey on Drug Use \& Health. 2011; 2013

Sutton S. Predicting and explaining intentions and behavior: How well are we doing? Journal of Applied Social Psychology. 1998; 28:1317-1338.

Sutton, S. Health behavior: psychosocial theories. In: Smelser, NJ.; Wright, J.; Baltes, PB., editors. International Encyclopedia of the Social and Behavioral Sciences. Oxford: Pergamon Press; 2001. p. 6499-6506.

U.S. Census Bureau. 2006-2010 American Community Survey 2013. 2010

Wall AM, Hinson RE, McKee SA. Alcohol outcome expectancies, attitudes toward drinking and the theory of planned behavior. Journal of Studies on Alcohol. 1998; 59:409-419. [PubMed: 9647423]

Wang J, Falck RS, Li L, Rahman A, Carlson RG. Respondent-driven sampling in the recruitment of illicit stimulant drug users in a rural setting: findings and technical issues. Addict Behav. 2007; 32:924-937. [PubMed: 16901654]

Wechsberg WM, Zule WA, Riehman KS, Luseno WK, Lam WK. African-American crack abusers and drug treatment initiation: barriers and effects of a pretreatment intervention. Subst Abuse Treat Prev Policy. 2007; 2:10. [PubMed: 17394653]

Weisner C. The alcohol treatment-seeking process from a problems perspective: responses to events. Br J Addict. 1990; 85:561-569. [PubMed: 2346796]

Westerhof GJ, Maessen M, de Bruijn R, Smets B. Intentions to seek (preventive) psychological help among older adults: An application of the theory of planned behaviour. Aging and Mental Health. 2008 May.12:317-322. [PubMed: 18728944]

Williams DR, Williams-Morris R. Racism and mental health: the African American experience. Ethn Health. 2000; 5:243-268. [PubMed: 11105267] 


\section{HIGHLIGHTS}

- The Theory of Planned Behavior is useful to identify correlates of perceived need for cocaine treatment

- Belief in treatment effectiveness was the strongest correlate of perceived need

- One measure of perceived control over drug use, readiness for treatment, was significantly associated with perceived need

- Attitudes and beliefs about drug use elucidate treatment motivation 
Table 1

Comparison of Rural and Urban African American Cocaine Users.

\begin{tabular}{|c|c|c|c|}
\hline Variable & Rural $(n=200)$ & Urban $(n=200)$ & Total \\
\hline Male & $61.5 \%$ & $65.0 \%$ & $63.2 \%$ \\
\hline High School Graduate or GED* & $62.5 \%$ & $73.0 \%$ & $67.7 \%$ \\
\hline Married or living as married & $12.0 \%$ & $6.5 \%$ & $9.2 \%$ \\
\hline Employed part-time or full-time ${ }^{*}$ & $38.0 \%$ & $19.5 \%$ & $28.8 \%$ \\
\hline Age (mean, SD) & $39.1(12.1)$ & $39.4(10.8)$ & $39.3(11.5)$ \\
\hline Past 30 days' crack cocaine use (mean, SD) & $9.4(11.5)$ & $11.3(11.4)$ & $10.3(11.4)$ \\
\hline Past 30 days' powder cocaine use (mean, SD) ${ }^{* *}$ & $6.5(8.4)$ & $3.7(6.2)$ & $5.1(7.5)$ \\
\hline Past 30 days' marijuana use (mean, SD) ${ }^{* * *}$ & $13.9(12.8)$ & $8.9(11.0)$ & $11.4(12.2)$ \\
\hline Past 30 days' alcohol use (mean, SD) & $14.8(10.9)$ & $14.1(10.7)$ & $14.5(10.8)$ \\
\hline Lifetime drug treatment (yes/no) & $37.0 \%$ & $45.5 \%$ & $41.2 \%$ \\
\hline Drug treatment in past year (yes/no) & $8.5 \%$ & $10.5 \%$ & $9.5 \%$ \\
\hline Perceived need for cocaine treatment & $5.3(2.7)$ & $5.2(2.9)$ & $5.3(2.8)$ \\
\hline Readiness to change cocaine use ${ }^{* *}$ & $6.9(2.5)$ & $5.9(2.7)$ & $6.4(2.6)$ \\
\hline Perceived control to reduce/stop cocaine use & $6.9(2.1)$ & $6.5(2.0)$ & $6.7(2.1)$ \\
\hline Perceived effectiveness of treatment ${ }^{* *}$ & $6.6(2.7)$ & $5.9(2.6)$ & $6.3(2.6)$ \\
\hline Experiences of rejection ${ }^{*}$ & $2.7(1.7)$ & $2.3(1.8)$ & $2.5(1.8)$ \\
\hline Need for secrecy & $2.9(7.1)$ & $2.7(1.1)$ & $2.8(5.1)$ \\
\hline Positive cocaine expectancies & $76.6(27.2)$ & $75.2(24.0)$ & $75.9(25.6)$ \\
\hline Negative cocaine expectancies ${ }^{* *}$ & $42.8(40.6)$ & $38.9(37.1)$ & $40.8(14.1)$ \\
\hline \multicolumn{4}{|l|}{${ }^{*} P<0.05$} \\
\hline *** $P<0.01$ & & & \\
\hline
\end{tabular}

$\mathrm{SD}=$ standard deviation, $\%$ are column percents. Comparisons are chi-square tests of dichotomous variables and t-tests for continuous variables. 


\section{Table 2}

Bivariate Analysis for Perceived Need for Treatment.

\begin{tabular}{|c|c|c|}
\hline \multirow{2}{*}{ Variable } & \multicolumn{2}{|c|}{ Perceived Need } \\
\hline & Mean & SD \\
\hline \multicolumn{3}{|l|}{ Two sample Wilcoxon Rank-Sum Test } \\
\hline \multicolumn{3}{|l|}{ Location: } \\
\hline Rural & 5.3 & 2.7 \\
\hline Urban & 5.2 & 2.9 \\
\hline \multicolumn{3}{|l|}{ Gender: } \\
\hline Male & 5.3 & 2.8 \\
\hline Female & 5.2 & 2.9 \\
\hline High school graduate or GED & 5.1 & 2.8 \\
\hline No & 5.6 & 2.7 \\
\hline Married or living as married & 5.5 & 2.3 \\
\hline No & 5.2 & 2.8 \\
\hline Employed part-time or full-time ${ }^{* *}$ & 4.7 & 2.7 \\
\hline No & 5.5 & 2.8 \\
\hline Prior drug treatment ${ }^{* * *}$ & 6.2 & 2.8 \\
\hline No & 4.6 & 2.6 \\
\hline \multicolumn{3}{|l|}{ Spearman Correlation for continuous variables } \\
\hline $\mathrm{Age}^{\mathrm{c}}$ & \multicolumn{2}{|c|}{0.30} \\
\hline Readiness to change cocaine use ${ }^{* * *}$ & \multicolumn{2}{|c|}{0.38} \\
\hline Perceived control to reduce/stop cocaine use & \multicolumn{2}{|c|}{0.09} \\
\hline Perceived effectiveness of treatment ${ }^{* * *}$ & \multicolumn{2}{|c|}{0.50} \\
\hline Experiences of rejection ${ }^{* * *} a$ & \multicolumn{2}{|c|}{0.37} \\
\hline Perceived devaluation $^{a}$ & \multicolumn{2}{|c|}{0.06} \\
\hline Perceived discrimination ${ }^{a}$ & \multicolumn{2}{|c|}{0.09} \\
\hline Need for secrecy ${ }^{*} a$ & \multicolumn{2}{|c|}{0.11} \\
\hline Positive cocaine expectancies ${ }^{* * b}$ & \multicolumn{2}{|c|}{0.15} \\
\hline Negative cocaine expectancies $* * * b$ & \multicolumn{2}{|c|}{0.28} \\
\hline \multicolumn{3}{|l|}{${ }^{*} P<0.05$} \\
\hline \multicolumn{3}{|l|}{${ }^{* *} P<0.01$} \\
\hline \multicolumn{3}{|l|}{$* * * * 0.0001$} \\
\hline${ }^{a}$ Subscale of items from Link et al (24). & & \\
\hline
\end{tabular}


Table 3

Results of Multiple Linear Regression Analysis for Perceived Need for Cocaine Treatment.

\begin{tabular}{lcccc}
\hline Variable & Regression coefficient + 95\% confidence interval & Standardized regression coefficient & P value \\
\hline Male & -0.04 & $-0.50,0.40$ & 0.01 & NS \\
Age & 0.04 & $0.02,0.06$ & 0.15 & $<0.001$ \\
Rural & -0.50 & $-0.94,-0.06$ & -0.09 & 0.025 \\
Attitudes and Beliefs & & & 0.39 & $<0.001$ \\
Effectiveness of treatment & 0.41 & $0.32,0.50$ & 0.13777 & 0.003 \\
Negative cocaine expectancies & 0.03 & $0.01,0.04$ & & $<0.001$ \\
Perceived Control & & & 0.15 & $<0.001$ \\
Readiness for treatment & 0.16 & $0.06,0.25$ & & 0.002 \\
Perceived Norms & & & 0.18 & 0.12 \\
Experiences of rejection & 0.29 & $0.15,0.42$ & \\
Need for secrecy & 0.30 & $0.10,0.49$ & & \\
\hline
\end{tabular}

